\title{
Family number in common bean selection
}

\author{
Wilton Duarte Ferreira ${ }^{1}$, Magno Antonio Patto Ramalhol, Daniel Furtado Ferreira ${ }^{2}$ and Moacil Alves de Souza ${ }^{1}$
}

\begin{abstract}
The objective of the present study was to determine the number of families necessary for selection in a segregant population. Nine segregant populations from the bean improvement program of the Federal University of Lavras were evaluated. The number of families varied from 169 to 295 , and the average family heritability estimate $\left(\mathrm{h}^{2}\right)$ for grain production varied from 5.3 to $82.0 \%$. Different sample sizes were simulated using the average family performance. The first sample consisted of 30 families, with each additional sample containing 10 more families, until the total number of families evaluated was reached for each population. One thousand simulations per sample size were performed. These data were used to determine the average, minimum and maximum phenotypic variance and the standard error of the variance. The probability of occurrence of a certain level of phenotypic variance for the corresponding values of $0.0,0.25,0.50$ and 0.75 of heritability was determined for all families, using a $\chi^{2}$ distribution. Based on the results obtained and considering the experimental precision and conditions of the bean improvement programs in this region, the use of less than 100 families would reduce the probability of successful selection.
\end{abstract}

\section{INTRODUCTION}

Greater efficiency in plant breeding programs is of utmost importance so that selection gains can meet the ever increasing demand for food. This efficiency may be achieved by various approaches, such as criteria-based progenitor choice, the method of segregant population advance and improvements in experimental precision during family evaluation.

Since all breeding programs have limited resources, one must decide whether it is best to perform several hybridizations yearly with a reduced number of families or fewer hybridization but with a larger number of families in order to explore the maximum variability generated in each crossing.

Several studies have determined the ideal number of families necessary for greater breeding efficiency (Sneep, 1977; Fouilloux and Bannerot, 1988; Huehn, 1996), although the results of these studies were obtained from simulations. Fouilloux and Bannerot (1988), for example, showed that plant breeding success is basically the same when one uses a relatively small $(50)$ or large $(>500)$ number of families. The main restriction in this case was that heritability was considered to be $100 \%$, an unrealistic finding in practice.

In the case of the common bean in Brazil, there is considerable variation in the number of families evaluated in segregant population studies (Marques Jr., 1997). In this study, we examined the effect of segregant population sample size on the efficiency of the selective process.

\section{MATERIAL AND METHODS}

Data from experiments with the common bean carried out at the Federal University of Lavras (UFLA) over the last few years were used. The results of nine experiments were used. Six were from biparental crossings, and the others were families from a recurrent selection program (Table I). Culture treatments were basically the same in all experiments and did not differ from standard procedures for common bean culture.

Grain production $(\mathrm{kg} / \mathrm{ha})$ for all experiments was analyzed by analysis of variance. From the expected mean squares, estimates were obtained for genetic variance among families $\left(\sigma_{\mathrm{G}}^{2}\right)$, phenotypic variance among family means $\left(\sigma^{2} \overline{\mathrm{F}}\right)$, and heritability in the broad sense $\left(\mathrm{h}^{2}\right)$ with lower and upper limits estimated by the expressions presented by Knapp et al. (1985).

Using adjusted means, different sample sizes were evaluated in each simulation, starting with 30 families and increasing the sample size by 10 families in each step. These simulations were performed using one thousand samples of the same size. The phenotypic variance between the family means was estimated for each group of samples. The average variance, the maximum and minimum values, the range of the means $(\mathrm{RM})$ and the variance standard error were also estimated.

Using the $\chi^{2}$ distribution, the probability of the occurrence of a phenotypic variance among family means was estimated by the expression: $\chi^{2}=\frac{(\mathrm{n}-1) \mathrm{s}_{\mathrm{i}}^{2}}{\sigma_{\overline{\mathrm{F}}}^{2}}$, where $\mathrm{n}$ is the sample size, $\mathrm{s}_{\mathrm{i}}^{2}$ is the value of the intended phenotypic variance for the different sample sizes and $\sigma_{\bar{F}}^{2}$ is the value of the phenotypic variance between family means (Chase and Brown, 1992).

The value of $s^{2}$ was determined by considering the probability of obtaining heritability estimates at least equal 
Table I - The genetic material, number of families, number of replications, statistical design, plot size, average grain yield, coefficient of variation (CV\%), and heritability $\left(\mathrm{h}^{2}\right)$ estimates with upper (UL) and lower (LL) limits for common bean grain production ( $\mathrm{kg} / \mathrm{ha}$ ).

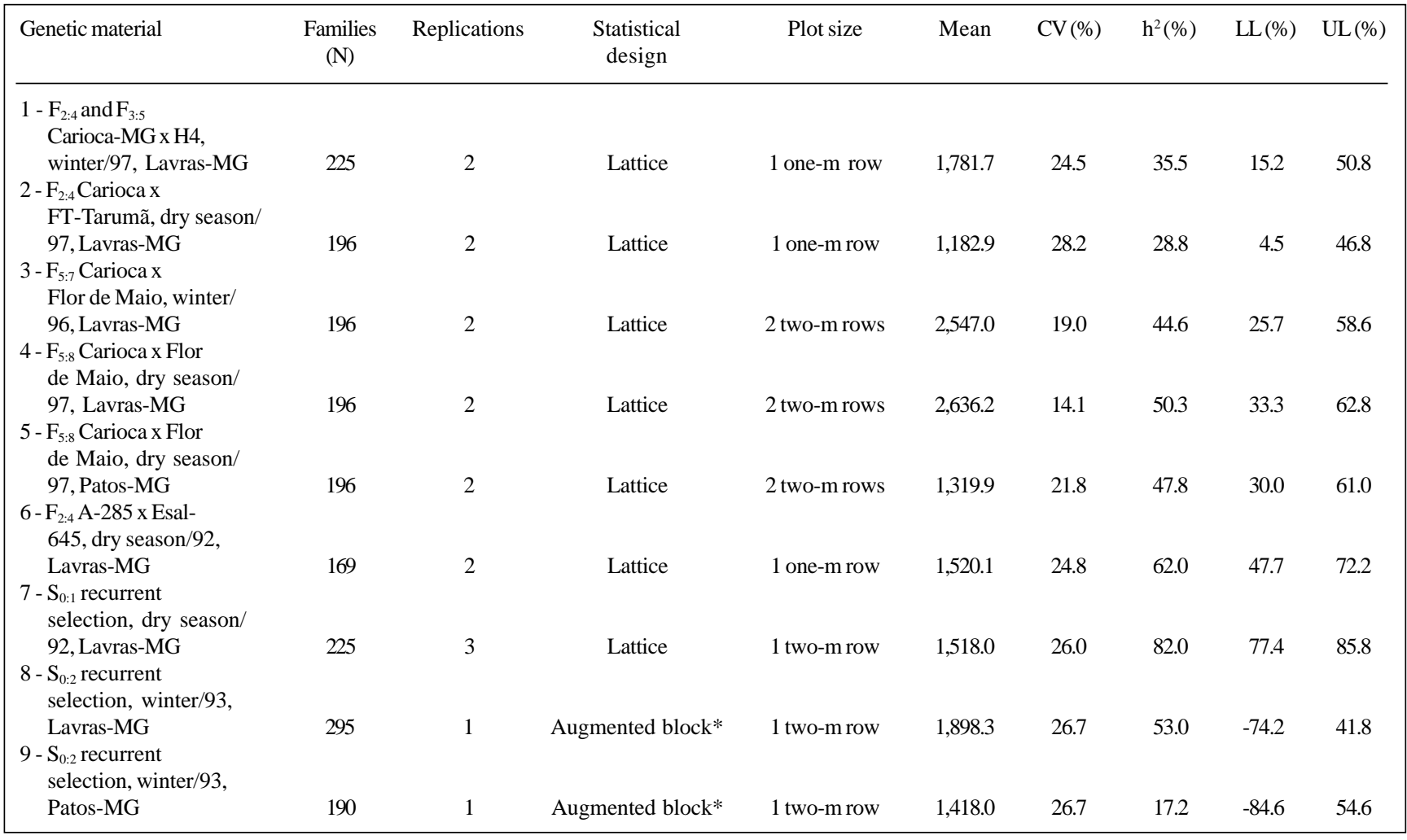

*: Two common controls were used.

to $0.0,0.25,0.50$ and 0.75 of the heritability estimate obtained using all the families evaluated for each population. The starting point for obtaining $\mathrm{s}^{2}{ }_{\mathrm{i}}$ was the expression that estimates heritability at the level of family means $\left(\mathrm{h}^{2}\right)$, such that, $h^{2}=\frac{\sigma_{\mathrm{G}}^{2}}{\sigma_{\mathrm{G}}^{2}+\sigma_{\mathrm{e}}^{2} / \mathrm{r}}$. For different proportions (x) of the heritability $\left(\mathrm{h}_{\mathrm{i}}^{2}\right), \mathrm{h}_{\mathrm{i}}^{2}=\mathrm{xh}^{2}=\frac{\sigma_{\mathrm{G}_{\mathrm{i}}}^{2}}{\sigma_{\mathrm{G}_{\mathrm{i}}}^{2}+\sigma_{\mathrm{e}}^{2} / \mathrm{r}}=\frac{\sigma_{\mathrm{G}_{\mathrm{i}}}^{2}}{\mathrm{~s}_{\mathrm{i}}^{2}}$, where $\sigma_{\mathrm{G}_{\mathrm{i}}}^{2}$ is the estimate of genetic variance among families of different sample sizes and corresponds to $\sigma_{\mathrm{G}_{\mathrm{i}}}^{2}=\mathrm{h}_{\mathrm{x}}^{2} \sigma_{\mathrm{F}}^{2}$. The parameter $x$ can assume the values of $0.0,0.25,0.50$ and 0.75 of $h^{2}$. Consequently, $\hat{s}_{i}^{2}=\sigma_{\mathrm{G}_{i}}^{2}+\sigma_{\mathrm{e}}^{2} / \mathrm{r}$, where $\sigma_{\mathrm{e}}^{2} / \mathrm{r}$ was considered constant and corresponded to the error mean square of the analyses of variance divided by the number of replications.

\section{RESULTS AND DISCUSSION}

The number of families evaluated varied from 169 to 295 . Based on the coefficient of variation (CV), the experimental precision was higher in the evaluation of $\mathrm{F}_{5: 8}$ families in the Carioca $x$ Flor de Mayo crossing and lower for $\mathrm{F}_{2: 4}$ families from the Carioca $\mathrm{x}$ FT-Tarumã crossing (Table I).
In spite of the large number of families evaluated, the precision of these experiments was similar to that usually obtained in common bean culture experiments in the region. In an analysis of 61 evaluation experiments of pure lines and 28 trials of family evaluations, Marques Jr. (1997) obtained an average CV of $20.7 \%$ for lines in the recommendation phase, and $27.2 \%$ for cases in which segregant families were evaluated.

Heritability estimates in the broad sense varied from $5.3 \%$ for $\mathrm{S}_{0: 2}$ families with recurrent selection to $82 \%$ for $\mathrm{S}_{0: 1}$ families. The largest $\mathrm{h}^{2}$ estimate was obtained in experiments done in augmented blocks, i.e., in which families under recurrent selection were evaluated, as shown by the lower limit (LL) and upper limit (UL) values (Table I).

The phenotype variance estimates were based on simulations using family means from the Carioca-MG x H4 crossing (Table II), and clearly reflect the influence of the other simulations. The average variances of the different sample sizes were basically the same as the variance estimated using all of the families. This was expected, since 1,000 replications of each sample size were simulated.

With the reduction in sample size, the range of phenotypic variance increased. The percentage of variance in the different sample sizes related to that obtained for all the families combined, showed that the nine populations behaved similarly. For example, in a sample size of 30 fami- 
Table II - Phenotypic variances (average, minimum and maximum) for grain yield ( $\mathrm{kg} / \mathrm{ha}$ ) for different sample sizes. The standard error of the variance, range of the means (RM) and the standardized selection intensity (i) are also shown for the $\mathrm{F}_{2: 4}$ and $\mathrm{F}_{3: 5}$ families from the Carioca- $\mathrm{Mg} \times \mathrm{H} 4$ crossing.

\begin{tabular}{|c|c|c|c|c|c|c|c|c|}
\hline \multirow[t]{2}{*}{ Sample size } & \multicolumn{5}{|c|}{ Phenotypic variance } & \multirow{2}{*}{$\begin{array}{l}\text { Standard error } \\
\text { of variance }\end{array}$} & \multirow[t]{2}{*}{$\mathrm{RM}$} & \multirow[t]{2}{*}{$\mathrm{i}$} \\
\hline & Average $\left(\sigma^{2} \bar{F}\right)$ & Minimu & $\left(\sigma_{\bar{F}_{M I N}}^{2}\right)$ & Maximur & $\left(\sigma^{2} \bar{F}_{M A X}\right)$ & & & \\
\hline 30 & 149133.7 & 58389.8 & $(39.4)^{1}$ & 322026.0 & $(217.3)^{1}$ & 41254.0 & 159.5 & 2.1 \\
\hline 40 & 147657.9 & 63839.6 & $(43.1)$ & 259023.7 & (174.8) & 33512.4 & 169.6 & 2.2 \\
\hline 50 & 147671.3 & 72737.4 & (49.1) & 266655.8 & (179.9) & 30399.3 & 179.1 & 2.3 \\
\hline 60 & 148771.2 & 64957.9 & (43.8) & 226154.4 & (152.6) & 26441.6 & 187.7 & 2.4 \\
\hline 70 & 148122.3 & 87769.2 & (59.2) & 239363.3 & (161.5) & 23372.7 & 193.0 & 2.5 \\
\hline 80 & 148567.7 & 92618.5 & $(62.5)$ & 215942.8 & (145.7) & 21300.7 & 199.9 & 2.6 \\
\hline 90 & 148347.0 & 89397.0 & (60.3) & 209604.4 & (141.4) & 19952.6 & 203.9 & 2.6 \\
\hline 100 & 148547.5 & 106364.4 & (71.8) & 200190.9 & (135.1) & 17064.6 & 210.0 & 2.7 \\
\hline 110 & 147515.1 & 103810.0 & (70.0) & 194211.8 & (131.0) & 16268.6 & 211.8 & 2.8 \\
\hline 120 & 148190.0 & 106227.9 & (71.7) & 193578.3 & (130.6) & 14934.6 & 216.0 & 2.8 \\
\hline 130 & 149281.6 & 105048.8 & (70.9) & 185107.3 & (124.9) & 13897.3 & 220.3 & 2.9 \\
\hline 140 & 148129.2 & 101771.1 & (68.7) & 180623.9 & (121.9) & 12525.8 & 222.4 & 2.9 \\
\hline 150 & 147506.9 & 111602.7 & (75.3) & 180876.2 & (122.0) & 11250.3 & 224.7 & 2.9 \\
\hline 160 & 148213.7 & 117494.8 & (79.3) & 172974.5 & (116.7) & 9758.8 & 228.4 & 3.0 \\
\hline 170 & 148264.7 & 113841.6 & (76.8) & 170205.1 & (114.8) & 8965.6 & 229.5 & 3.0 \\
\hline 180 & 148307.0 & 113660.8 & (76.7) & 167875.3 & (113.3) & 8098.2 & 231.0 & 3.0 \\
\hline 190 & 148376.6 & 124471.8 & (84.0) & 164081.6 & (110.7) & 6508.9 & 232.6 & 3.0 \\
\hline 200 & 148301.5 & 124532.7 & $(84.0)$ & 160431.1 & (108.3) & 5504.4 & 233.8 & 3.0 \\
\hline 210 & 148516.4 & 126322.4 & $(85.2)$ & 157009.0 & (105.9) & 4136.5 & 234.9 & 3.1 \\
\hline 220 & 148166.4 & 133133.2 & (89.8) & 151540.8 & (102.3) & 2440.7 & 235.6 & 3.1 \\
\hline 225 & 148200.1 & 148200.1 & (100.0) & 148200.1 & (100.0) & - & - & - \\
\hline
\end{tabular}

${ }^{1}$ Percentage in relation to the largest sample size.

lies, the minimal phenotypic variance was on average $63.8 \%$ lower than the populational variance. On the other hand, the maximum variance was $101.6 \%$ greater than this value. With a sample size of 100 , the minimal phenotypic variance was less than $33 \%$ of the populational variance, and the maximum was about $35 \%$ greater than this value.

In general, the standard error of the variances increased as sample size decreased. Thus, for a sample size of 30 , the average variance standard error was $26.6 \%$ of the populational phenotypic variance, while for a sample size of 100 , this value was only $11 \%$ of the variance.

The probability of obtaining null heritability decreased as sample size increased (Figures 1-3). For a sample size of 100 , the probability was essentially zero, except for $S_{0: 2}$ recurrent selection families in Lavras, which had a probability of $4.8 \%$, and the $\mathrm{S}_{0: 2}$ generation recurrent selection families in Patos de Minas, which had a probability greater than $10.0 \%$.

The same tendency was observed for the probability of obtaining heritabilities of 0.25 and 0.50 of the populational estimate. In all cases, the probability of not obtaining a heritability 0.75 of the populational value increased as sample size decreased. For a sample size of 30 , this value varied from $20.6 \%$ in the $\mathrm{S}_{0: 1}$ generation from the recurrent selection program in Lavras (Figure 3A) to $47.5 \%$ in the Carioca-MG x H4 crossings $\left(\mathrm{F}_{2: 4}\right.$ and $\mathrm{F}_{3: 5}$ generations) (Figure 1A). Under similar conditions, but with a sample size of 100 , the probability was lower, varying from $5.1 \%$ in the $\mathrm{S}_{0: 1}$ generation of recurrent selection in Lavras (Figure 3A) to $39.9 \%$ in the $\mathrm{S}_{0: 2}$ generation of recurrent selection families in Patos de Minas (Figure 3C).

The simulations also showed the variation in average grain yield of the families studied (Table II). In general, the grain yield range decreased as sample size decreased. Using the values for grain yield range and heritability already mentioned, it was possible to predict the gain expected with selection using the expression GS $=\mathrm{ds} * \mathrm{~h}^{2}$. Considering selection of the family with the highest average for each sample size, the selection differential (ds) would be given by $\mathrm{ds}=\mathrm{RM} / 2+\mathrm{m}-\mathrm{m}$, where $\mathrm{m}$ is the general average, such that $\mathrm{ds}=\mathrm{RM} / 2$. Since the average phenotypic variance was the same for all sample sizes and the environmental variance was constant, the heritability between family means can be considered constant for all sample sizes. Thus, the difference in the expected gain with selection will be a function of only RM/2. Consequently, the gain with selection will be greater as the number of families evaluated increases. With 220 families, the gain was $235.6 \mathrm{~kg} / \mathrm{ha}$. With 30 families, it was $159.5 \mathrm{~kg} / \mathrm{ha}$. Therefore, the gain with selection, using 220 families $\left(\mathrm{GS}_{220}\right)$, would be 1.48 times greater than that obtained with 30 families $\left(\mathrm{GS}_{30}\right)$ since $\mathrm{GS}_{220} / \mathrm{GS}_{30}=\left(\mathrm{RM}_{220} / 2\right) \mathrm{h}^{2} /\left(\mathrm{RM}_{30} / 2\right) \mathrm{h}^{2}=235.6 / 159.5=1.48$.

Using the standardized selection index (i) defined by Falconer $(1980)$ as $\mathrm{i}=\mathrm{ds} / \sigma_{\overline{\mathrm{F}}}=\mathrm{RM} / 2 \sigma_{\overline{\mathrm{F}}}$, the gain with selection becomes GS $=i$. $\sigma_{{ }_{\mathrm{G}}}^{2} / \sigma_{\overline{\mathrm{F}}}$. Since $\sigma_{\mathrm{G}}^{2} / \sigma_{\overline{\mathrm{F}}}$ is constant, the gain is a function only of the $i$ value. For the CariocaMG x H4 crossing, $\mathrm{GS}_{220} / \mathrm{GS}_{30}=\mathrm{i}_{220} / \mathrm{i}_{30}=3.1 / 2.1=1.48$, which is the same as calculated above. 

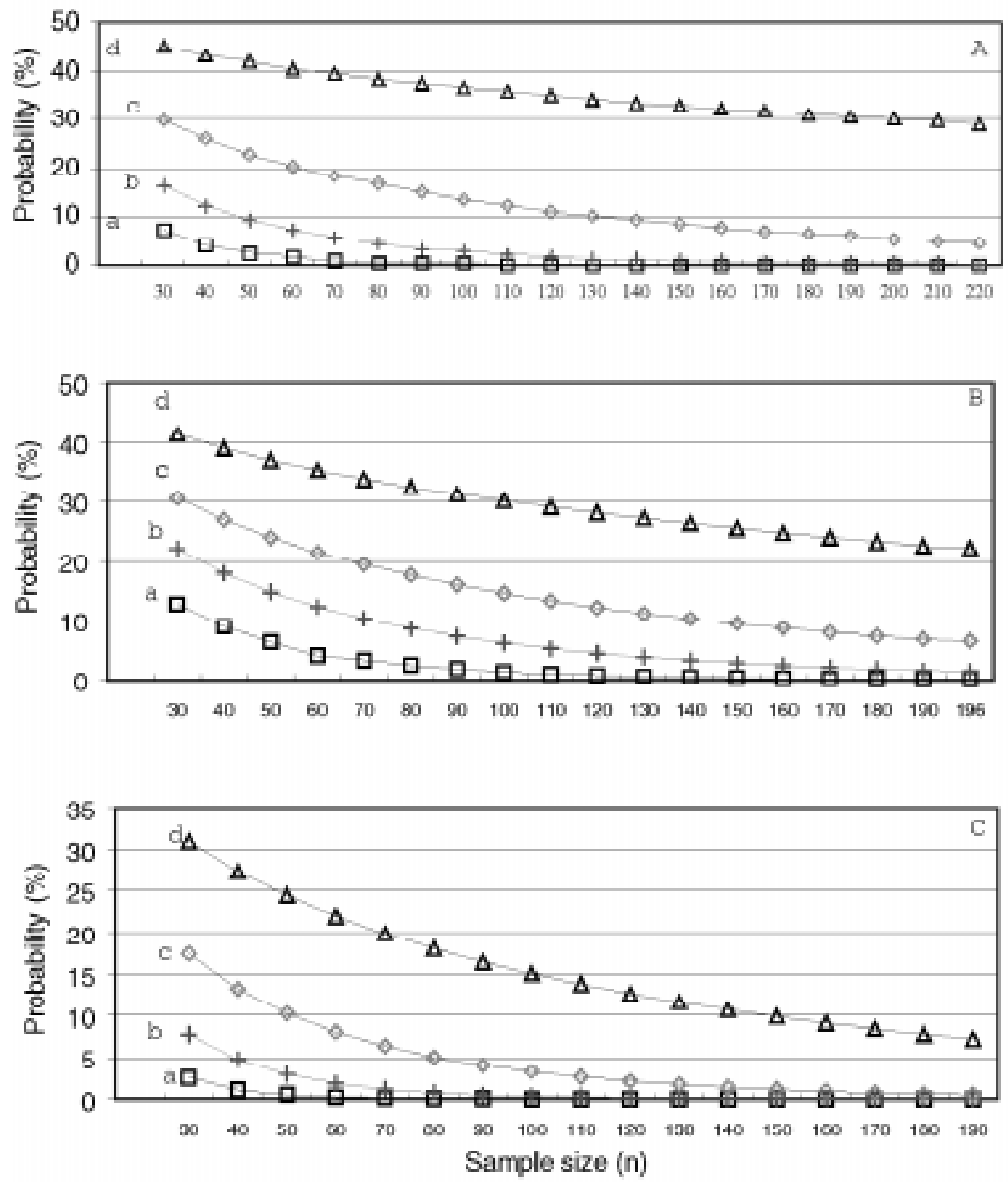

Figure 1 - Probability of populational heritability of grain productivity $\left(h^{2}\right) a=0.0 h^{2}, b=0.25 h^{2}, c=0.50 h^{2}$ and $d=0.75 h^{2}$. Families from the (A) Carioca-Mg x H4, (B) Carioca x FT-Tarumã and (C) Carioca x Flor de Mayo, during the winter of 1996 (Lavras, MG).

Again, when considering $\geq 100$ families, the differences in standardized selection intensity were small. In the Carioca-MG x H4 crossing, $\mathrm{i}_{100}=2.7$ and $\mathrm{i}_{220}=3.1$ (Table II), thus $\mathrm{GS}_{220} / \mathrm{GS}_{100}=1.15$. In other words, with an increase from 100 families to 220 families, the average increase in the expected gain with selection would only be $15 \%$. In this situation, it is questionable whether an increase of 2.2-fold in the number of families is compensatory. Since the number of families used in common bean studies is generally lower (Marques Jr., 1997) than in the experiments described here, our results should reflect the situation in most breeding programs for this species.

Some studies have shown that for a fixed number of experimental plots that can be manipulated by the plant breeder, it is preferable to evaluate a greater number of crossings at the expense of a lower number of families from each crossing. Cooper (1988) suggested 100 crossings per year for soybeans. Starting with the $\mathrm{F}_{2: 3}$ generation, 30 families per crossing should be evaluated with selection between and within families.

Proposals such as the above and simulation studies such as that of Fouilloux and Bannerot (1988) show that selection can be successful with a small number of families. However, the results described here showed that when using less than 100 families, the chances of null heritability (an absence of gain with selection) can be high. The av- 

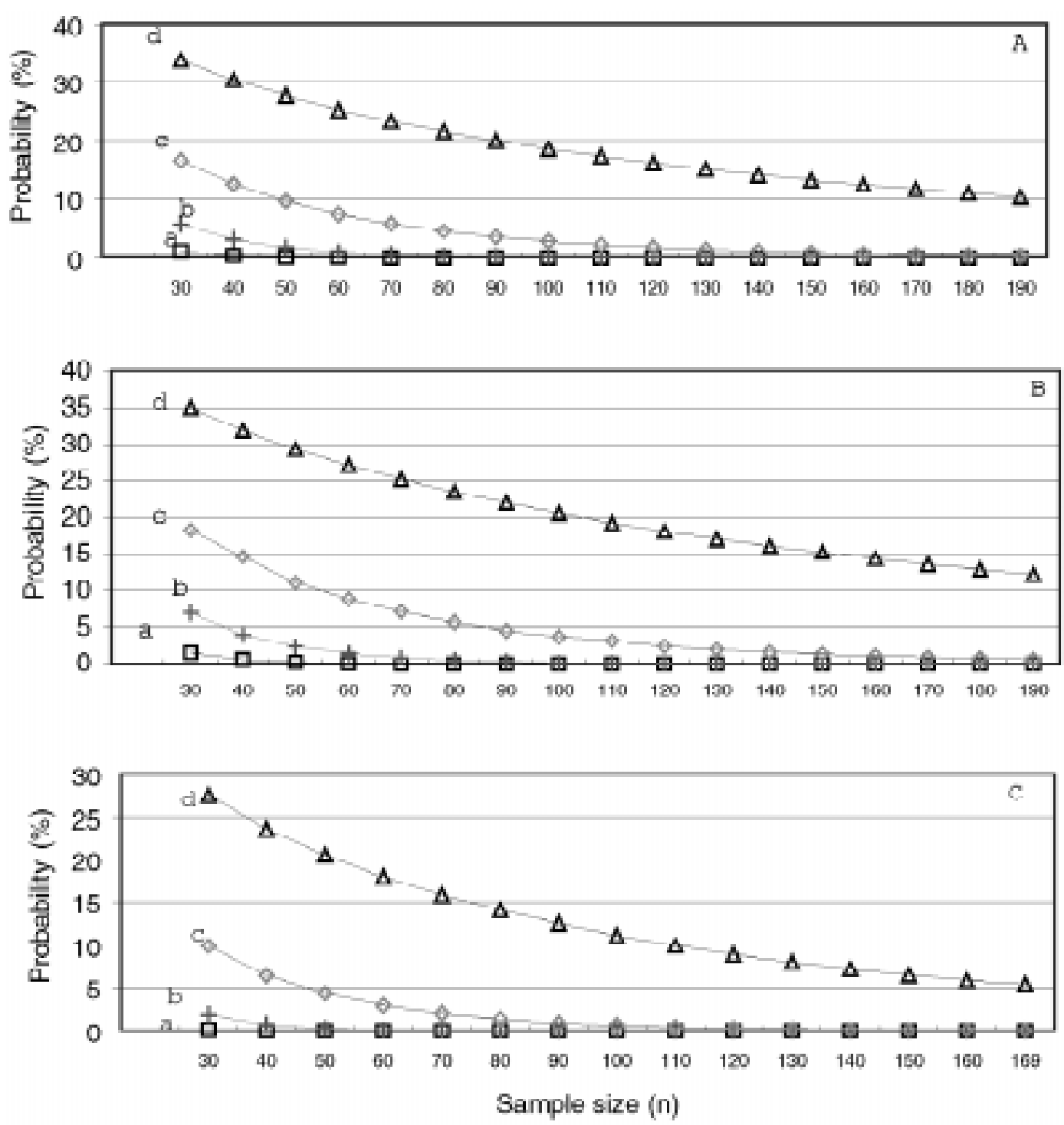

Figure 2 - Probability of populational heritability of grain productivity $\left(h^{2}\right) a=0.0 h^{2}, b=0.25 h^{2}, c=0.50 h^{2}$ and $d=0.75 h^{2}$. Families from the (A) Carioca x Flor de Mayo crossing, during the dry season of 1997 (Lavras, MG), (B) Carioca x Flor de Mayo crossing, during the dry season of 1997 (Patos de Minas, MG) and (C) A-285 x Esal-645 crossing.

erage probability in nine populations with 30 families each was $8.14 \%$. This percentage increases when one considers the probability of not detecting sizeable heritability, equivalent to $0.50-0.75$ of the populational value. The observations in relation to gain with selection also highlight this fact. In principle, when using a small number of families, the probability of a successful selection is less, especially when variability is low.

There are, however, procedures that make the early choice of more promising segregant populations possible (Jinks and Pooni, 1976; Abreu, 1997). In this case, working with a limited number of crossings allows one to explore the available variability in greater depth. To achieve this, a larger number of families is necessary. As shown above, this number should be greater than 100 .

Some reports have shown that most breeders' success occurs when good lines are crossed with good lines (Rasmusson and Phillips, 1997). In this case, the mean of the segregant populations is high because of the already adapted lines involved, but the liberated variability is low, because the divergence between them is generally limited. Thus, for successful selection, plant breeders should be able to explore the low variability available. For this to happen, the family evaluation experiments must be as precise as possible, and a greater number of families needs to be evaluated. 

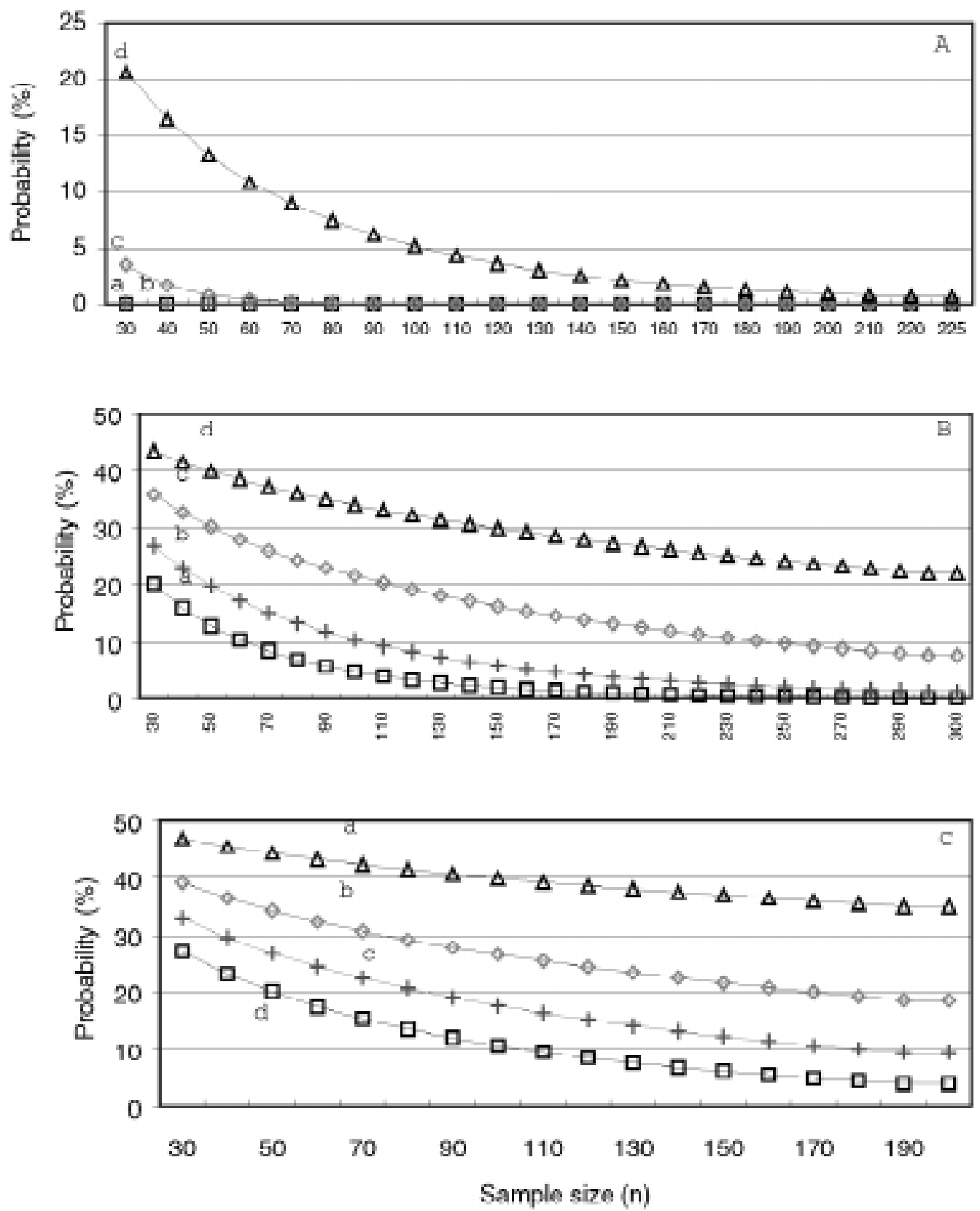

Figure 3 - Probability of populational heritability of grain productivity $\left(h^{2}\right) a=0.0 h^{2}, b=0.25 h^{2}, c=0.50 h^{2}$ and $d=0.75 h^{2}$. (A) $S_{0: 1}$ families from the recurrent selection, (B) $\mathrm{S}_{0: 2}$ families from the recurrent selection, during the winter of 1993 (Lavras, MG) and (C) $\mathrm{S}_{0: 2}$ families from the recurrent selection, during the winter of 1993 (Patos de Minas, MG).

\section{ACKNOWLEDGMENTS}

Publication supported by FAPEMIG.

\section{RESUMO}

O objetivo desse trabalho foi obter informações que possam auxiliar os melhoristas de feijão, quando da decisão sobre a escolha do número de famílias de uma população segregante que deverá ser avaliada para maior eficiência com a seleção. Para isso, utilizaram-se dados experimentais de avaliação de nove populações segregantes do programa de melhoramento do feijoeiro da Universidade Federal de Lavras, conduzidos no período de 1992 a 1997, com o número de famílias variando de 169 a 295 e com a estimativa de herdabilidade $\left(\mathrm{h}^{2}\right)$ para a produtividade de grãos, na média das famílias, no intervalo de 5.3 a $82.0 \%$. Utilizando o desempenho médio das famílias, foram simulados diferentes tamanhos de amostras, variando de $10 \mathrm{em} \mathrm{10,} \mathrm{a} \mathrm{partir} \mathrm{de} \mathrm{tamanho}$ 30, até o número total de famílias avaliadas em cada caso. Foram efetuadas 1.000 simulações para cada tamanho de amostra. Com os dados foram estimados a variância fenotípica média, a mínima, a máxima e o erro padrão da variância. Utilizando a distribuição de 
$\chi^{2}$ foi estimada a probabilidade de ocorrência de um dado valor da variância fenotípica entre média das famílias, para cada tamanho de amostra, considerando $\mathrm{h}^{2}$ nula, ou com valores correspondentes a $0.25,0.50$ ou 0.75 da herdabilidade obtida com todas as famílias sendo avaliadas. Constatou-se que, nas condições da precisão experimental em que são conduzidos os programas de melhoramento do feijoeiro na região, com a utilização de um número de famílias inferiores a 100, a probabilidade de sucesso com a seleção é reduzida.

\section{REFERENCES}

Abreu, A. de F.B. (1997). Predição do potencial genético de populações segregantes do feijoeiro utilizando genitores inter-raciais. $\mathrm{PhD}$ thesis, UFLA, Lavras.

Chase, W. and Brown, F. (1992). General Statistics. 2nd edn.John Wiley and Sons Inc., New York.

Cooper, R.L. (1988). Mejoramiento por rendimiento en soya: prueba de generacion temprana y adaptacion especifica a ambientes de alto rendimiento versus ambientes de bajo rendimiento. In: Temas Actuales en Mejoramiento Genético del Frijol Comum (Beebe, S., ed.). CIAT, Cali, pp. 301-323.

Falconer, D.S. (1980). Introdução à Genética Quantitativa. UFV, Viçosa.

Fouilloux, G. and Bannerot, H. (1988). Selection methods in common bean (Phaseolus vulgaris L.). In: Genetic Resources of Phaseolus Beans (Gepts, P., ed.). Klüwer Academic Publishers, Dordrecht, pp. 503-541.

Huehn, M. (1996). Optimum number of crosses and progeny per cross in breeding self-fertilizing crops. I. General approach and first numerical results. Euphytica 91: 365-374.

Jinks, J.L. and Pooni, H.S. (1976). Predicting the properties of recombinan inbred lines derived by single seed descent. Heredity 36: 253-266.

Knapp, S.J., Stroup, W.W. and Ross, W.M. (1985). Exact confidence intervals for heritability on a progeny mean basis. Crop Sci. 25: 192-194.

Marques Jr., O.G. (1997). Eficiência de experimentos com a cultura do feijão. $\mathrm{PhD}$ thesis, UFLA, Lavras.

Rasmusson, D.C. and Phillips, R.L. (1997). Plant breeding progress and genetic diversity from de novo variation and elevated epistasis. Crop Sci. 37: 303-310.

Sneep, J. (1997). Selection for yield in early generations of self-fertilizing crops. Euphytica 26: 27-30.

(Received July 3, 1998) 
